\title{
IMOBILIZAÇÃO DE PEROXIDASE DE RAIZ FORTE EM MICROESFERAS DE ALGINATO DE SÓDIO POR ADSORÇÃO FÍSICA NA PRESENÇA DE LÍQUIDOS IÔNICOS IMIDAZÓLIOS
}

\author{
F. M. S. SANTOS ${ }^{1}$, R. M. C. DOS SANTOS ${ }^{1}$, M. N. MELO ${ }^{1}$, Á. S. LIMA ${ }^{1}$, H. M. \\ ALVAREZ $^{2}$, C. M. F. SOARES ${ }^{1}$ e A. T. FRICKS ${ }^{1}$ \\ ${ }^{1}$ Universidade Tiradentes, Instituto de Tecnologia e Pesquisa \\ ${ }^{2}$ Universidade Estadual de Feira de Santana, Departamento de Ciências Exatas \\ Email para contato: flaviabiotec@gmail.com
}

\begin{abstract}
RESUMO - O presente trabalho teve como objetivo avaliar o efeito da presença de líquidos iônicos (LIs) baseados no cátion imidazol $\left(\left[\mathrm{C}_{4} \operatorname{mim}\right] \mathrm{TF}_{2} \mathrm{~N}\right),\left[\mathrm{C}_{4} \mathrm{mim}\right] \mathrm{BF}_{4},\left[\mathrm{C}_{4} \mathrm{mim}\right] \mathrm{PF}_{6}$, $\left[\mathrm{C}_{4} \mathrm{mim}\right] \mathrm{HSO}_{4}$ e $\left.\left[\mathrm{C}_{4} \mathrm{mim}\right] \mathrm{Ac}\right)$ na imobilização de peroxidase de raiz forte (PRF) em microesferas de alginato por adsorção física. A metodologia envolve a imersão das esferas de alginato em hexano seguida da adição de terc-butanol e preparação enzimática $\left(24 \mathrm{~h} / 4^{\circ} \mathrm{C}\right)$. A imobilização de PRF na presença de LIs na concentração de $1 \%(\mathrm{~m} / \mathrm{v})$ foi conduzida com carregamento de $0,16 \mathrm{mg}$ de PRF/g de microesferas. A imobilização de PRF em microesferas de alginato na ausência de LIs forneceu 9,35\% de recuperação de atividade (RA) enquanto na presença de $\left[\mathrm{C}_{4} \mathrm{mim}\right] \mathrm{Tf}_{2} \mathrm{~N}$ a RA foi aumentada em cerca de 5 vezes (RA 50\%). O uso de LI durante o processo de adsorção da enzima em microesferas de alginato de cálcio validou a imobilização da enzima por esta metodologia.
\end{abstract}

\section{INTRODUÇÃO}

As peroxidases estão amplamente distribuídas em animais, plantas e no corpo humano. As peroxidases (E.C. 1.11.1.7), ubíquas na natureza, ou seja, presentes em todos os seres vivos são oxidases que não dependem de cofatores e utilizam peróxido de hidrogênio para oxidar uma grande variedade de compostos orgânicos e inorgânicos (HUNSAI et al., 2009 e ZHU et al., 2001).

A capacidade de oxidação de compostos fenólicos por peroxidases torna esta uma das reações mais difundidas como aplicação destas enzimas, tanto na química ambiental quanto em síntese orgânica. Assim, peroxidases podem ser aplicadas na síntese de polímeros fenólicos e copolímeros a partir de uma ampla gama de fenóis. A síntese enzimática destes polímeros tem como vantagens as condições reacionais brandas e ausência de formação de produtos secundários (PARVULESCU et al., 2011). A peroxidase de raiz forte (PRF) é amplamente aplicada no setor ambiental para monitoramento de contaminantes em efluentes provenientes das indústrias devido a sua capacidade de catalisar a oxidação de compostos fenólicos.

A dificuldade em se recuperar a enzima do meio reacional ao final da catálise, aliada à instabilidade e frequente inadequabilidade para uso em determinados solventes e/ou condições de 
$\mathrm{pH}$, temperatura e exposição a agentes desnaturantes, podem ser superadas por meio da imobilização. A imobilização da PRF permite a utilização da enzima em processos oxidativos em geral e confere algumas vantagens importantes tais como: maior estabilidade, permite que a enzima atue em faixas mais amplas de temperaturas e pHs. Desta forma o biocatalisador imobilizado pode proporcionar maior eficiência e tempo de meia vida durante as condições reacionais selecionadas para cada aplicação de interesse em diferentes processos industriais. De maneira geral a enzima imobilizada pode ser reutilizada e é normalmente mais estável em relação à enzima livre, com a vantagem adicional de possibilitar a realização de um processo contínuo.

É fundamental que os materiais utilizados como suporte sejam encontrados com facilidade e em abundância na natureza, tenham custo baixo, facilidade operacional em grande escala, resistência mecânica para uma longa vida útil e baixa ou nenhuma toxicidade. Nesse contexto os biopolímeros, como alginato, quitina, quitosana, agarose, agar e outros, são considerados suportes ideais para imobilização de enzimas.

Para melhorar a eficiência catalítica do biocatalisador imobilizado, uma das estratégias utilizadas é o uso do aditivo. Entre os aditivos utilizados no processo de imobilização, merece destaque o uso dos LIs. Sendo assim o objetivo do presente trabalho foi imobilizar a PRF em microesferas de alginato de cálcio pela metodologia de adsorção física na presença e ausência de LIs (LI) imidazólicos e avaliar o efeito dos LI nesse sistema imobilizado.

\section{MATERIAL E MÉTODOS}

A atividade enzimática foi determinada por método colorimétrico, baseado na mudança de absorvância a $470 \mathrm{~nm}$ devido à formação do produto de oxidação do guaiacol, o tetraguaiacol durante três minutos. O ensaio continha tampão fosfato de sódio $100 \mathrm{mM}(\mathrm{pH} 6,0) ; 0,04 \mathrm{~mL}$ do preparado enzimático (solução estoque de PRF: 0,32 mg/mL) diluído 200 vezes; $0,1 \mathrm{~mL}$ de solução de guaiacol $100 \mathrm{mM}$ e $0,1 \mathrm{~mL}$ de $\mathrm{H}_{2} \mathrm{O}_{2} 2,0 \mathrm{mM}$, a $25^{\circ} \mathrm{C}$. O volume total de reação: $3 \mathrm{~mL}$. Para dosagem de atividade das amostras imobilizadas, cerca de $8 \mathrm{mg}$ foram utilizados e foi feita a leitura pontual da absorvância em $470 \mathrm{~nm}$ após 3 minutos de reação.

Uma unidade de enzima (U) foi definida como a quantidade de enzima capaz de fornecer 1 $\mu$ mol de produto em $1 \mathrm{~min}$ a $25^{\circ} \mathrm{C}$, no $\mathrm{pH}$ específico para esta reação. $\varepsilon_{\text {tetraguaiacol }}: 26,6 \mathrm{mM}^{-1} \mathrm{~cm}^{-1}$ (HIRATA et al., 1998).

A peroxidase de raiz forte foi imobilizada por adsorção física em esferas de alginato de cálcio. As esferas foram obtidas por gotejamento de solução aquosa de alginato de sódio $5 \%$ em cloreto de cálcio $1 \mathrm{M}$, mantida em agitação branda por aproximadamente $2 \mathrm{~h}$, formando as microesferas de alginato de cálcio e em seguidas foram lavadas com água destilada para a retirada do excesso de cloreto de cálcio e moléculas secas em estufa a $40^{\circ} \mathrm{C}$ durante. Foi verificada a influência do carregamento da enzima na recuperação da atividade na faixa de $0,08-0,65 \mathrm{mg}$ $\mathrm{PRF} / \mathrm{g}$ suporte. Todos os experimentos foram realizados em triplicata.

A recuperação de atividade $(R A)$ foi determinada pelo número de unidades de atividade enzimática total presente no suporte $(U s)$ comparado às unidades de atividade peroxidásica oferecidas para imobilização $(U o)$, conforme Equação 1: 
$R A(\%)=\frac{U_{S}}{U_{0}} \times 100$

Utilizando o carregamento mais adequado foram conduzidas as imobilizações de PRF na presença de LIs $\left(\left[\mathrm{C}_{4} \mathrm{mim}\right] \mathrm{TF}_{2} \mathrm{~N} ;\left[\mathrm{C}_{4} \mathrm{mim}\right] \mathrm{BF}_{4} ;\left[\mathrm{C}_{4} \mathrm{mim}\right] \mathrm{HSO}_{4} ;\left[\mathrm{C}_{4} \mathrm{mim}\right] \mathrm{Ac}\right.$ e $\left.\left[\mathrm{C}_{4} \mathrm{mim}\right] \mathrm{PF}_{6}\right)$, que foi simultaneamente adicionado com a enzima na proporção de $1 \%(\mathrm{~m} / \mathrm{v})$ com respeito ao volume total da reação de imobilização. A escolha da concentração de $1 \%(\mathrm{~m} / \mathrm{v})$ de LIs foi baseada em estudos prévios publicados pelo grupo de pesquisa (SOUZA et al., 2012 e 2013).

As esferas de alginato de cálcio $(0,5 \mathrm{~g})$ previamente secas em estufa a $40^{\circ} \mathrm{C}$ por $2 \mathrm{~h}$ foram suspensas em $10 \mathrm{~mL}$ de hexano, mantidas sob agitação mecânica por $15 \mathrm{~min}$. Em seguida adicionou-se solução de PRF preparada em tampão fosfato $100 \mathrm{mM}$ pH 6,0 e $2 \mathrm{~mL}$ de tertbutanol. $\mathrm{O}$ sistema foi mantido sob agitação por $3 \mathrm{~h}$ a $25^{\circ} \mathrm{C}$, e em seguida armazenado a $4{ }^{\circ} \mathrm{C}$ em condição estática, durante 24 h. O imobilizado foi filtrado e lavado com hexano para retirada da enzima não adsorvida.

\section{RESULTADOS E DISCUSSÃO}

\subsection{EFEITO DO CARREGAMENTO DA PRF}

A influência do carregamento da enzima imobilizada por adsorção física foi estudada na faixa de 0,08-0,65 mg PRF/g de suporte selecionados e os resultados são mostrados na Tabela 1 .

$\mathrm{Na}$ adsorção física o melhor carregamento também foi de $0,16 \mathrm{mg} \mathrm{PRF} / \mathrm{g}$ de suporte com RA de 9,35\% (Tabela 1). Na imobilização por adsorção a enzima interage com o suporte por meio de interações intermoleculares fracas (Mendes et al., 2011). Os grupamentos hidroxila dos anéis piranosídicos do suporte podem interagir por meio de ligações de hidrogênio com grupamentos carboxilatos livres da enzima conforme sugerido na Figura 1.

Tabela 1. Estudo da influência do carregamento de PRF na imobilização por adsorção.

\begin{tabular}{|c|c|c|c|}
\hline $\begin{array}{c}\text { Carregamento } \\
\text { (mg PRF/g de suporte) }\end{array}$ & UA & $\begin{array}{c}\text { A .Total } \\
(\mathbf{U})\end{array}$ & $\begin{array}{c}\text { RA } \\
(\%)\end{array}$ \\
\hline 0,65 & 15,79 & 0,44 & $2,97 \pm 0,20$ \\
\hline 0,32 & 7,89 & 0,508 & $5,26 \pm 1,31$ \\
\hline 0,16 & 3,94 & 0,60 & $9,35 \pm 0,08$ \\
\hline 0,08 & 1,97 & 0,04 & $1,88 \pm 0,20$ \\
\hline
\end{tabular}

UA - Unidades totais de atividade adicionada (U)

A. Total - (Atividade do biocatalisador imobilizado) X (massa seca do biocatalisador imobilizado).

RA - Recuperação de atividade (\%), calculada pela equação (1). 


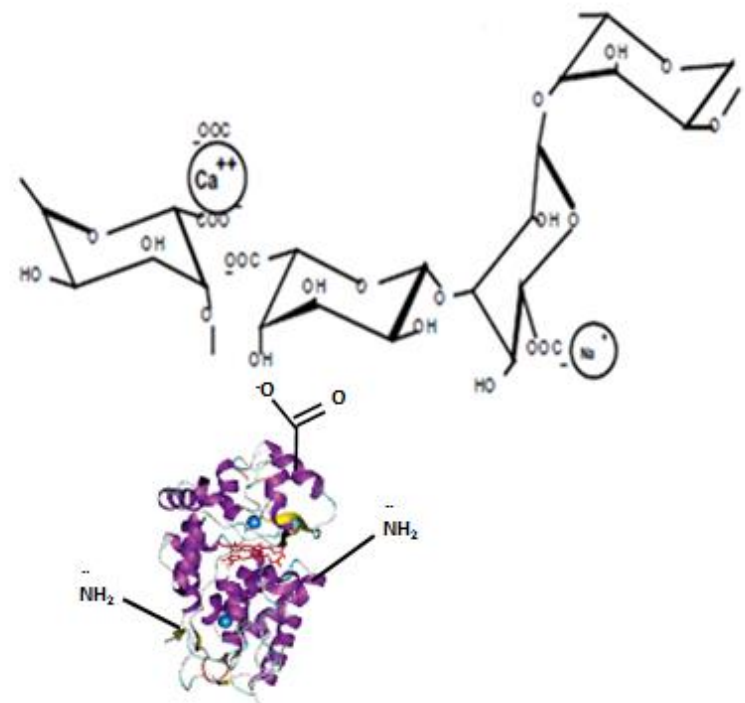

Figura 1. Esquema de imobilização da PRF nas microesferas de alginato de cálcio por adsorção.

\subsection{IMOBILIZAÇÃO DE PRF EM ALGINATO NA PRESENÇA DE LI}

$\mathrm{Na}$ imobilização por adsorção física a presença de LI propiciou um aumento de cinco vezes na recuperação da atividade (Tabela 2).

Tabela 2. Estudo da influência de LIs na imobilização da HRP pela metodologia de adsorção física.

\begin{tabular}{|c|c|c|c|c|c|}
\hline \multirow{2}{*}{$\begin{array}{c}\text { Ausência de } \\
\mathbf{L I}\end{array}$} & {$\left[\mathbf{C}_{\mathbf{4}} \mathbf{m i m}\right] \mathbf{T F}_{\mathbf{2}} \mathbf{N}$} & {$\left[\mathbf{C}_{\mathbf{4}} \mathbf{m i m}\right] \mathbf{B F}_{\mathbf{4}}$} & {$\left[\mathbf{C}_{\mathbf{4}} \mathbf{m i m}\right] \mathbf{P F}_{\mathbf{6}}$} & {$\left[\mathbf{C}_{\mathbf{4}} \mathbf{m i m}\right] \mathbf{A c}$} & {$\left[\mathbf{C}_{\mathbf{4}} \mathbf{m i m}\right] \mathbf{H S O} \mathbf{H}_{\mathbf{4}}$} \\
\hline $9,35 \pm 0,08$ & $50,42 \pm 3,0$ & $46,89 \pm 2,5$ & $45,19 \pm 2,5$ & $38,93 \pm 3,03$ & $1,47 \pm 0,02$ \\
\hline
\end{tabular}

A presença de $\left[\mathrm{C}_{4}\right.$ mim $] \mathrm{Tf}_{2} \mathrm{~N}$ propiciou maior $\mathrm{RA}(50,42 \%)$, seguido do $\left[\mathrm{C}_{4} \mathrm{mim}\right] \mathrm{BF}_{4} \mathrm{e}$ $\left[\mathrm{C}_{4} \mathrm{mim}\right] \mathrm{PF}_{6}$ com 46,89 e 45,19\%, respectivamente. Enquanto com $\left[\mathrm{C}_{4} \mathrm{mim}\right] \mathrm{Ac} \mathrm{RA}$ foi de $38,93 \%$ e com $\left[\mathrm{C}_{4} \mathrm{mim}\right] \mathrm{HSO}_{4}$ de apenas $1,47 \%$. Em geral, LIs hidrofóbicos tendem a acumularse na porção não polar da enzima formando bolsões hidrofóbicos não disponibilizando o sítio ativo da enzima, o que constitui o principal obstáculo no que tange à utilização de LIs como solvente em biocatálise, pois a hidratação superficial da enzima pode ser reduzida (NAUSHAD et al., 2012; VENTURA et al., 2012). Os LIs utilizados neste trabalho possuem característica predominantemente hidrofóbica, em se tratando de sua porção catiônica [C4mim]. No entanto, a natureza do ânion do LI pode modificar a forma com que a enzima se comporta no meio reacional: íons pequenos e com alta densidade eletrônica (cosmotrópicos) são capazes de quebrar ligações de hidrogênio da água e permitir que estas solvatem o cátion, enquanto íons grandes e carregados com cargas simples (caotrópicos) permitem maior liberdade às moléculas de água (ZHAO et al., 2006). Nessa última enquadram-se os ânions $\mathrm{PF}_{6}^{-}, \mathrm{BF}_{4}^{-}, \mathrm{Tf}_{2} \mathrm{~N}^{-}$.

Naushad et al. (2012) relatam em seu trabalho o impacto do ânion do LI sobre a estabilidade e a atividade da enzima através da sua capacidade de ligação de hidrogênio. De acordo com a 
literatura foi observado que o ânion tendo uma alta capacidade de formação de ligação de hidrogênio interage fortemente com a enzima, gerando mudança conformacional na estrutura da enzima afetando a sua atividade (MARIE et al., 2010).

Marie et al. (2010) estudaram a influência do ânion do LI na atividade da lipase na reação de flavonóides com ácidos graxos de cadeia longa. Neste estudo foi verificado que o LI contendo ânions $\mathrm{Tf}_{2} \mathrm{~N}^{-}, \mathrm{PF}_{6}^{-}$, e $\mathrm{BF}_{4}^{-}$foram bem sucedidos como meios de reação, enquanto LIs contendo ânion com forte capacidade de ligação de hidrogênio resultou em diminuição da produtividade.

A literatura relata menor interferência do $\mathrm{LI}\left[\mathrm{C}_{4} \mathrm{mim}\right] \mathrm{Ac}$ na atividade da PRF devido a porção aniônica do LI ser derivado de ácido fraco $\left(\mathrm{H}_{3} \mathrm{CCO}_{2} \mathrm{H}\right)$, menos ávido a romper ligações de hidrogênio na estrutura da enzima. No entanto a região aniônica deste LI possui características hidrofílicas o que pode ter influenciado de maneira negativa na atividade da enzima, uma vez que, há diminuição de moléculas de água ao redor da enzima. (QUEIROZ et al., 2012).

Nos experimentos realizados na presença do $\mathrm{LI}\left[\mathrm{C}_{4} \mathrm{mim}\right] \mathrm{HSO}_{4}$ observou-se a redução na atividade da enzima imobilizada na presença deste LI, embora este tenha se apresentado imiscível em água. $\mathrm{O}$ resultado corrobora com dados da literatura que mostram a inativação de lipase na presença de $\left[\mathrm{C}_{4} \mathrm{mim}\right] \mathrm{HSO}_{4}$ (MARTÍN et al., 2008).

\section{CONCLUSÕES}

Os resultados do efeito do carregamento na recuperação da atividade da PRF imobilizada por adsorção física em microesferas de alginato de cálcio mostram que o carregamento ótimo para enzima imobilizada por este método foi $0,16 \mathrm{mg} \mathrm{PRF} / \mathrm{g}$ de suporte. Com base nos resultados podemos concluir que a utilização de LIs imidazólios no preparo do biocatalisador propiciou um aumento significativo na RA $9,35 \%$ para $50,42 \%$ na ausência e presença de $\mathrm{LI}\left[\mathrm{C}_{4} \mathrm{mim}\right] \mathrm{Tf}_{2} \mathrm{~N}$, respectivamente.

\section{REFERÊNCIAS BIBLIOGRÁFICAS}

HIRATA, T.; IZUMI, S.; OGURA, M.; YAWATA, T. Epoxidation of styrenes with the peroxidase from the culture cells of Nicotianatabacum, Tetrahedron, 54, p. 15993-16003, 1998.

HUSAIN Q.; KULSHRESTHA Y. Bioaffinity-based an inexpensive and high yield procedure for the immobilization of turnip (Brassica rapa) peroxidase, Biomolecular Engineering, 23: p. 291-297, 2009.

MARIE-B, L.; GUO, Z.; XU, X. Effect of room temperature ionic liquid structure on the enzymatic acylation of flavonoids, Process Biochemistry, 45, p. 1375-1382, 2010.

MARTÍN, J. R.; NUS, M.; GAGO J. V. S.; SÁNCHEZ-MONTERO J. M. Selective esterification of phthalic acids in two ionic liquids at high temperatures using a thermostable lipase of Bacillus thermocatenulatus: A comparative study, Journal of Molecular Catalysis B: Enzymatic, 52, p. 162-167, 2008. 
MENDES, A. A.; FREITAS, L.; CARVALHO, A. K. F; OLIVEIRA, P. C.; CASTRO, H. F. Immobilization of a Commercial Lipase from Penicillium camembertii (Lipase G) by Different Strategies, Enzyme Research, 2011, p. 1-8, 2011.

NAUSHAD, M.; ALOTHMAN, Z. A.; KHAN, A. B., ALI, M. Effect of ionic liquid on activity, stability, and structure of enzymes: A review, International Journal of Biological Macromolecules, 51, p. 555- 560, 2012.

PARVULESCU, V. I.; BALA, C; STAN, R.; TEODORESCU, CRISTIAN.; MAHALU, DIANA.;TUDORACHE, M. Biocatalyticmicroreactor incorporating HRP anchored on micro/nano-lithographic patterns for flow oxidation of phenols, Journal of Molecular Catalysis B: Enzymatic, 69, p. 133-139, 2011.

QUEIROZ, M. L. B.; ALVAREZ, H. M.; BOAVENTURA, R. F.; CARVALHO, N. B.; SOARES, C. M. F.; LIMA, A. S.; HEREDIA, M. F.; DARIVA, C.; FRICKS, A. T. Effect of the presence of surfactant and ionic liquids on the esterification of oleic acid catalyzed by immobilized lipase, African Journal of Biotechnology, 11 (102), p. 16718-16724, 2012.

SOUZA, R. L., FARIA, E. L. P., FIGUEIREDO, R. T., FREITAS, L. S., IGLESIAS, M., MATTEDI, S., ZANIN, G.M., SANTOS, O. A. A., COUTINHO,J. A. P., LIMA, A. S., SOARES, C. M. F. Protic ionic liquid as additive on lipase immobilizationusing sol-gel, Enzymeand Microbial Technology, 52, p.141-150, 2013.

SOUZA, R. L.; RESENDE, W. C.; BARÃO, C. E.; ZANIN, G. M.; CASTRO, H. F.; SANTOS, O. A. A.; FRICKS, A. T.; FIGUEIREDO, R. T.; LIMA, A. S.; SOARES, C. M. F. Influence of the use of Aliquat 336 in the immobilization procedure in sol-gel of lipase from Bacillus sp. ITP-001, Journal Molecular Catalysis B: Enzymatic, 84, p. 152-159, 2012.

VEnTURA, S. P. M.; SANTOS, L. D. F; SARAIVA, J.; COUTINHO, J. A. P. Concentration effect of hydrophilic ionic liquids on the enzymatic activity of Candida antarctica lipase B, World Journal of Microbiology and Biotechnology, 28, p. 2303-2310, 2012.

ZHAO H.; OLUBAJO O.; SONG, Z.; SIMS, A. L.; PERSON, T. E.; LAWAL, R. A. BIOORG. Effect of kosmotropicity of ionic liquids on the enzyme stability in aqueous solutions .Bioorganic Chemistry. 34, p. 15-25, 2006.

ZHU, M.; HUANG, X.; SHEN, H. Aromaticazo compounds as spectrophotometric kinetic assay substrate for HRP, Talanta, 53, p. 927-935, 2001. 